\title{
PELAKSANAAN KERJA SAMA BISNIS \\ PADA USAHA DAGANG [UD] YUSUF BANGUNAN BATUSANGKAR
}

\author{
Yunimar \\ Mahasiswa Program Pascasarjana \\ Program Studi Hukum Ekonomi Syariah \\ Sekolah Tinggi Ilmu Agama Islam Negeri Batusangkar
}

\begin{abstract}
This study was purposed at describing the implementation of business cooperation UD. Yusuf; describing the conflicts were arisen from business cooperation at UD. Yusuf and describing the figh muamalah perspective for the resolution of UD. Yusuf. This study was called non-doctrinal research. Interview and documentation were used as instruments in this study. The qualitative data analysis was done this study by applying data reduction; data display; and conclusion drawing/verification. The findings concluded that the business cooperation UD. Yusuf was not based syariah, it was based on trust. The conflict on business cooperation UD. Yusuf should be overcome in Shulh, Tahkim, Wilayat Al Hisbah, or Al Qadha. Based on the figh muamalah perspective, it should be solved based on Al-Baqarah 282.
\end{abstract}

Keywords: The Implementation of Business Cooperation, Conflicts, Fiqh muamalah

\section{PENDAHULUAN}

Dalam hal berbisnis dengan kontrak atau akad bisnis syariah yang telah diatur sedemikian rupa guna menjamin terpenuhinya rasa keadilan bagi semua pihak yang terkait, dalam perjalanannya tidak menutup kemungkinan terjadinya hal-hal yang tidak memuaskan bagi sebagian pihak yang lain. Hal ini dikarenakan salah satu pihak atau sebagian pihak yang lain telah melakukan ingkar janji terhadap perjanjian yang telah dibuatnya sehingga pihak yang lain merasa dirugikan hak-haknya. Walaupun aktivitas ekonomi syariah telah dilaksanakan dengan mempertimbangkan prinsip-prinsip syariah, namun dalam proses perjalanannya tidak menutup kemungkinan terjadinya sengketa antara pihak-pihak yang bersangkutan.

Pada masa Rasul, beliau memutuskan perkara yang terjadi di tengah masyarakat, dalam berbagai perkara muamalah seperti ketika beliau mendapati pedagang di pasar yang mencampur gandum basah dengan gandum kering. Beliau sendiri yang melakukan aktivitas al-qadhấ (AlZuhaili, 1989: 740). Hukum perjanjian syariah merupakan suatu perikatan yang sengaja dibuat secara tertulis, sehingga dapat digunakan sebagai alat bukti bagi para pihak yang berkepentingan (Amzmus, 
2013). Perikatan (iltizam) dalam hukum Islam adalah terisinya dzimmah seseorang atau suatu pihak dengan suatu hak yang wajib ditunaikannya kepada orang atau pihak lain (Anwar, 2007: 49).

Sebagai bahan survey awal, peneliti meneliti sebuah kasus kerjasama bisnis yang berubah menjadi intimidasi kriminal debt colector pada Usaha Dagang (UD) Yusuf Bangunan Batusangkar yang dikelola oleh Usman. Awalnya berdiri dari sebuah usaha bisnis pertemanan dengan modal seluruhnya dari investor, namun perjanjian bisnis tidak dilakukan secara tertulis antara Usman dan Ajiz seorang pekerja kapal asing di Bakauheni dengan menyerahkan modal kepada pengelola sebanyak 1,5 milyar secara bertahap dalam kurun waktu tiga bulan (Hasil Wawancara dengan Usman tanggal 20 Maret 2014).

Kerjasama bisnis ini berkembang menjadi sewa rental mobil dan bus untuk wisata, dan beberapa pertokoan di luar Batusangkar. Pasca tiga tahun kerjasama bisnis muncul sengketa karena hak investor diambil alih oleh istrinya ketika beliau masih sakit-sakitan dan sekarang sudah almarhum. Maka pihak pengelola dipaksa untuk menyetor 50 juta tiap bulan sebagai angsuran utang. Sedangkan dari kesepakan awal perjanjiannya adalah kerjasama bisnis bukan utang piutang. Pihak pengelola tidak menyanggupi permintaan tersebut, maka pihak investor menyita semua asset usaha kerjasama selain yang di Batusangkar (Hasil Wawancara dengan Usman 20 Maret 2014).

Peneliti menilai kasus ini terjadi karena awal bisnis ini dilakukan dengan kontrak yang tidak jelas atau bisnis saling percaya karena pertemanan. Dari kasus tersebut peneliti mencoba menganalisis penyelesaian sengketa kerjasama bisnis UD. Yusuf Bangunan perspektif fikih muamalah.

\section{METODE PENELITIAN}

Penelitian ini adalah penelitian deskriptif dengan pendekatan kualitatif karena lebih bersifat deskriptif, sumber data utama dalam penelitian kualitatif adalah kata-kata dan tindakan, selebihnya adalah data tambahan seperti dokumen atau bahan lain (Moleong, 2007: 157). Penelitian kualitatif dalam penelitia ini dilakukan dengan mendeskripsikan bagaimana pelaksanaan kerja sama bisnis pada usaha dagang (UD) Yusuf Bangunan Batusangkar. Instumen penelitian yang digunakan dalam penelitian ini adalah wawancara, observasi dan dokumentasi. Teknik analisis data dalam penelitian ini adalah analisis data kualitatif, mengikuti konsep yang diberikan Miles dan Huberman. Miles 
dan Huberman mengemukakan bahwa aktivitas dalam analisis data kualitatif dilakukan secara interaktif dan berlangsung secara terus menerus pada setiap tahapan penelitian sehingga sampai tuntas, dan datanya sampai jenuh (Moleong, 2007: 307). Analaisis data yang dilakukan dalam penelitian ini dengan (1) mereduksi data yang meliputi mengumpulkan dan menghimpun sumber-sumber data terkait melalui wawancara dengan sumber data menggunakan media tulis, mencatat kembali hasil wawancara untuk kemudian ditranskripkan menggunakan bahasa yang tepat dan benar; (2) memaparkan atau menyajikan data dalam bentuk naratif; dan (3) menarik kesimpulan.

\section{HASIL PENELITIAN DAN PEMBAHASAN}

\section{Pelaksanaan Kerjasama Bisnis Pada \\ UD. Yusuf Bangunan}

\section{a. Pelaksanaan Kerjasama Karena}

\section{Unsur pertemanan.}

Usaha Dagang (UD) Yusuf Bangunan Batusangkar yang dikelola oleh Yulius yang lebih dikenal Usman sebagai nama panggilan sehari-hari. Awalnya berdiri dari sebuah usaha bisnis pertemanan karena saling mempercayai sehingga kerjasama tidak dilakukan secara tertulis antara Usman dan Ajiz seorang pekerja kapal asing di Bakauheni (Hasil Wawancara dengan Usman tanggal 5 Juli 2014).

Usman kenal dengan Ajiz pada tahun 1998 di Bakauheni Lampung Selatan, Usman bekerja sebagai sopir truk fuso antar pulau, dan Ajiz merupakan agen penyeberangan kapal di Bakauheni, perkenalan mereka awalnya karena Usman menolong Ajiz yang bermasalah dengan preman di terminal Merak Jakarta, dari perkenalan tidak sengaja itu menjadi persahabatan, setiap Usman ke Jakarta maka mereka selalu bertemu di Bakauheni, sebab Ajiz yang mengurus surat-surat mobil untuk naik kapal penyeberangan Bakauheni-Merak.

Pada tahun 2000 Usman berhenti membawa Truk, kemudian Ajiz meminta Usman datang ke Bakauheni untuk kembali bekerja bersama Ajiz. Mereka bekerja dengan orang China bernama Ahui, seorang pengusaha angkutan barang dan jasa, sedangkan Ajis adalah orang kepercayaan Ahui untuk mengurus semua keperluan penyebarangan antar pulau 
Sumatera-Jawa, Usman dipercaya mengawal pengiriman barang dari sumatera sampai pulau Bali dengan gaji yang cukup besar, Usman curiga mengapa mendapatkan gaji lebih besar dari biasanya dia dapatkan sebagai sopir truk, ternyata barang angkutan yang dikirimkannya adalah barang sokel (barang selundupan).

Selama tiga bulan bekerja dengan Ahui, Ajiz dan Usman sepakat untuk meninggalkan perkerjannya menjadi kaki tangan penyelundup, maka Ajis meminta Usman bekerjasama untuk membuat usaha dengan memberikan modal awal kepada Usman.

Usman membuat bisnis awalnya di Bakauheni, yakni Usaha memperjual belikan kayu dari pulau prajurit di Bakauheni ke Tanjung Karang Bandar Lampung, serta sayur mayur dari Lampung ke pasar induk Jakarta Timur, namun usaha Yulius alias Usman selalu bangkrut karena selalu ditipu oleh pemborong, barang sudah dikirim tetapi uang tidak pernah sesuai dengan perjanjian, akhirnya tahun 2010 Usman membuka usaha yakni
UD. Yusuf Bangunan di simpang tiga Batu Batikam Dusun Tuo nagari Limo Kaum.

b. Bentuk Akad Kerja Sama yang Dilakukan UD. Yusuf Bangunan

Menurut Usman bahwa Modal usaha seluruhnya dari Ajiz yang diberikan kepada Usman sebagai pengelola sebanyak 1,5 milyar secara bertahap dalam kurun waktu tiga bulan (Hasil Wawancara dengan Usman tanggal 5 Juli 2014). Beberapa modal usaha yang diberikan Ajiz kepada Usman adalah berupa truk, artinya tidak seluruh modal berupa uang tunai. Untuk mendirikan usaha bangunan hanya dengan menggunakan dana cash Rp.300.000.000 dan 2 unit truk, dengan penambahan modal sebesar Rp.500.000.000 dan Rp.400.000.000 dijadikan modal lagi oleh usman bersama temannya, tujuan Usman untuk memperluas usaha. Dari awal bisnis Ajis mempercayakan usaha secara penuh kepada Usman, Ajis hanya menerima keuntungan hasil usaha sesuai dengan kesepakatan yang telah mereka tentukan sebesar 40\% : $60 \%$, pembagian keuntungan dilakukan setiap tahun. Namun pada kenyataannya Ajis meminta 
Usman mentransfer uang kapan Ajis membutuhkannya tidak disebutkan apakah yang diminta transfer keuntungan usaha atau yang lainnya (Hasil Wawancara dengan Usman tanggal 5 Juli 2014).

Kerja Sama Usman dan Ajiz sampai 2012 berjalan lancar, Ajiz mulai mengalami sakit, badannya kurus dan selalu muntaber dan tidak bisa diobati, semakin hari tubuh Ajiz semakin kurus, sehingga Rika (istri Ajiz) yang menggantikan posisi Ajiz yang menyebabkan Usman merasa sudah tidak nyaman lagi berteman dengan Ajiz sebab setiap berurusan bisnis dengan Ajiz selalu Rika yang mengambil alih dan berbicara kasar kepada Usman seolah-olah Usman adalah pekerja Rika, Usman protes kepada Ajiz namun Ajiz tidak bisa berbuat banyak, beberapa bulan mereka putus komunikasi dan sampai terdengar kabar kalau Ajiz telah meninggal dunia (Hasil Wawancara dengan Usman tanggal 5 Juli 2014).

\section{c. Perubahan Perjanjian Secara} Sepihak Menjadi Utang Piutang

Pasca meninggalnya Ajiz maka kerjasama bisnis muncul sengketa karena hak Ajiz sebagai investor diambil alih oleh istri Ajiz yaitu Rika sejak beliau masih sakit-sakitan dan sekarang sudah almarhum. Maka Usman sebagai pihak pengelola diminta untuk menyetor 50 juta setiap bulan sebagai angsuran utang, karena menurut Rika bahwa uang bisnis itu hanya pinjaman dan keuntungannya adalah berupa bunga atas pinjaman tersebut (Hasil Wawancara dengan Rika, Istri Ajis tanggal 10 Juli 2014). Sedangkan dari kesepakatan awal perjanjian antara Usman dan Ajiz adalah kerjasama bisnis bukan utang piutang. Pihak Usman tidak menyanggupi permintaan tersebut, akhirnya Rika mulai menyita semua asset usaha kerjasama yang di Batusangkar dan menurut Usman dirinya adalah korban.

\section{Bentuk Konflik Yang Ditimbulkan Dari Sengketa Kerjasama Bisnis pada UD. Yusuf Bangunan}

a. Penyitaan surat tanah serta sertifikat rumah milik keluarga pengelola (Usman) oleh Investor (Rika); dan

b. Ancaman terhadap pihak pengelola dan keluarga yang dilakukan oleh pihak investor. 
3. Perspektif Fiqh Muamalah terhadap Penyelesaian Sengketa Bisnis Pada UD. Yusuf Bangunan.

a. Shulh (Berdamai).

Langkah pertama yang perlu diupayakan ketika hendak menyelesaikan perselisihan ialah melalui cara damai. Untuk mencapai hakekat perdamaian, prinsip utama yang perlu dikedepankan adalah kesadaran para pihak untuk kembali kepada Allah dan RosulNya dalam menyelesaikan segala persoalan.

Upaya damai tersebut biasanya ditempuh melalui musyawarah (syuura) untuk mencapai mufakat di antara para pihak yang bersengketa. Dengan musyawarah yang mengedepankan prinsipprinsip syari'at, diharapkan apa yang menjadi persoalan para pihak dapat diselesaikan.

Shulh adalah Akad antara dua orang yang yang berselisih atau bersengketa untuk menyelesaikan perselisihan diantara keduanya. Ada beberapa macam shulh antara lain 1) shulh karena pengakuan (berdamai karena adanya pengakuan); 2) shulh karena penolakan; dan 3) shulh karena diam.
Shulh karena diam pada sengketa UD. Yusuf Bangunan dapat diilustrasikan dengan tuduhan Usman terhadap Rika yang mengingkari kerjasama usaha, kemudian Rika hanya berdiam tidak mengakuinya serta tidak pula menolaknya, kemudian Rika mengajak Usman sebagai pengelola berdamai dengan memberinya sesuatu misalnya sejumlah uang tunai supaya pengelola (Usman) membatalkan pengakuannya dan menghindari permusuhan.

Menurut peneliti penyelesaian sengketa dengan cara shulh yang menjadi patokannya adalah pemberian dari pihak tertuduh untuk mencabut tuduhannya. Artinya, kerugian materi tidak ada perhitungan lagi karena pihak investor sudah memberikan sesuatu berupa imbalan untuk pengelola agar menarik tuduhannya dan selesailah masalah.

\section{b. Tahkim (Arbitrase)}

Institusi formal yang khusus dibentuk untuk menangani perselisihan/sengketa disebut arbitrase, yaitu cara penyelesaian sengketa perdata di luar peradilan 
umum yang didasarkan pada perjanjian arbitrase yang dibuat secara tertulis oleh para pihak yang bersengketa yaitu Usman dan Rika. Adapun mengenai keputusan, sekiranya arbiter terdiri dari tiga orang, maka setiap keputusan atau ketetapan harus brdasarkan suara terbanyak, sekiranya suara terbanyak tidak tercapai, maka ketua arbiter bisa menjatuhkan keputusan sendiri dan dianggap dibuat oleh semua anggota arbiter. Keputusan arbiter ini harusnya bersifat final dan mengikat (final and binding) (Iska, 2012: 292).

\section{c. Wilayat Al Hisbah}

Wilāyah al-hisbah adalah suatu institusi yang sudah ada sejak zaman pemerintahan Rasulullah S.A.W. di Madinah, walaupun pada waktu itu nama al-hisbah tidak dikenal secara resmi. Umpamanya, bagi mereka yang bertugas mengawasi perjalanan perniagaan di pasar dikenal sebagai 'Pengawas Pasar' (Sahib al-sūq) atau 'Petugas di Pasar' (al-Amil fi alSüq). Keberadaan wilāyah al-hisbah ini diteruskan oleh pemerintahan Islam selanjutnya dengan peranan yang lebih luas. Ada di antara pemerintah menamainya dengan al-hisbah, tetapi terdapat juga nama lain yang digunakan sebagaimana nama-nama yang telah peneliti sebutkan di atas. Biar apa pun nama yang diberikan, wilāyah al-hisbah ini tetap eksis dalam pemerintahan Islam karena ia adalah salah satu sendi utama pemerintahan Islam yang berdiri dengan konsep al-amr bi al-ma 'rüf wa al-nahy an al-munkar.

$$
\text { al-Gazali (1991: 357) }
$$
memaparkan tingkatan dalam mengambil tindakan yang dilakukan oleh al-muhtasib antara lain sebagai berikut.

1) Menyadarkan atas buruk baiknya suatu perbuatan, metode yang digunakan adalah nasehat,

2) Memperingatkan agar mengerjakan perbuatan yang

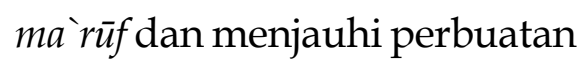
yang mungkar,

3) Mengancam dengan hukuman, baik dengan menyebutkan hukuman-hukuman Tuhan maupun hukuman-hukuman negara,

4) Berkata keras kalau perlu menghardiknya supaya ia sadar atas kesalahannya, 
5) Menyuruh atau melarang sesuatu dengan tangan, jika pihak yang bersalah masih tidak dapat disadarkan dengan ancaman. Al-Muhtasib bisa juga menggunakan tangan atau kekuasaan (al-tagyir bi al-yad).

6) Memberikan hukuman prefentif untuk menyadarkannya seperti melarang berjualan di pasar, mengusir penghuni rumah yang tidak memiliki izin resmi, dan sebagainya.

7) Menggunakan sebatan/ cambuk dan menahan (aljild wa al-habs). Pemukulan tersebut juga dilakukan dengan tidak membahayakan anggota tubuhnya.

8) Menggunakan para aparat keamanan atau kekuatan senjata. Tindakan ini perlu dilakukan jika orang yang melanggar undang-undang itu orang yang kuat atau berkuasa dan mencoba melawan dengan menggunakan kekerasan.

9) Mengenakan berbagai bentuk hukuman ta'zir. Hukuman ta zir ini boleh dilaksanakan dengan berbagai bentuk baik itu memukul, memenjarakan, menyingkirkan, menjatuhkan atau mengumumkan kesalahan orang tersebut di khalayak ramai. Kekuasaan ta'zir ini diserahkan kepada al-muhtasib dan hukuman yang dijatuhkan setimpal dengan kesalahan yang dilakukan.

\section{d. Al Qadha (Peradilan)}

Jika melalui shulh dan arbitrase sengketa ini tidak dapat diselesaikan maka dapat diselesaikan selanjutnya di tingkat peradilan, yang mana untuk sekarang adalah Peradilan Agama sesuai dengan disahkannya UU No. 3 Tahun 2006 tentang perubahan UU No. 7 Tahun 1989 Penyelesaian sengketa diperadilan melalui alat bukti yang lengkap seperti alat bukti tertulis, alat bukti saksi, alat bukti persangkaaan, alat bukti pengakuan, alat bukti sumpah, pemeriksaan setempat, saksi ahli/ Pendapat ahli.

Menurut pendapat peneliti kerja sama UD. Yusuf Bangunan ini karena dibuat tidak secara tertulis dan tanpa adanya saksi maka alat bukti yang dapat digunakan adalah 
pengakuan, persangkaan hakim, dan sumpah dari kedua pihak yang bersengketa, pemeriksaan setempat, dan saksi ahli.

e. Analisis Fiqh Muamalah terhadap Pelaksanaan Kerjasama UD. Yusuf Bangunan

Pelafalan perjanjian yang dilakukan pada kerja sama antara Ajiz dan Usman diungkapkan dengan bentuk ucapan dan kehendak dari Ajiz dengan menyerahkan modal kepada Usman dan kesiapan dari Usman untuk mengelola dengan menerima modal tersebut, namun pelafalan perjanjian ini tidak diikuti secara tertulis/berbadan hukum. Transaksi mudharabah dianggap sah dengan perkataan dan perbuatan yang menunjukkan maksudnya. Jadi dari sisi pelafalan perjanjian kerja sama telah dilaksanakan. Namun sesuai dengan QS AlBaqarah ayat 282 dan 283 kerja sama ini harus dibuat juga dalam bentuk tertulis dengan tujuan untuk menghindari jika suatu saat terjadi wanprestasi. Akan tetapi fiqh muamalah membolehkan tidak menuliskan perjanjian kerja sama dengan dasar saling mempercayai.

\section{KESIMPULAN}

Temuan penelitian menyimpulkan bahwa kerja sama yang terjadi pada UD. Yusuf tidak sesuai dengan syariah, karena hanya berdasarkan kepercayaan. Konflik kerja sama yang terjadi pada UD. Yusuf harus diselesaikan melalui Shulh, Tahkim, Wilayat Al Hisbah, or Al Qadha. Menurut fiqh muamalah, konflik tersebut harus diselesaikan berdasarkan QS. Al-Baqarah 282.

\section{KEPUSTAKAAN ACUAN}

Al-Gazali, Abu Hamid Muhammad bin Muhammad. (1991). Ihya' Ulum alDin, Beirut: Dar al-Fikr.

Al-Jaza'iri, Syaikh Abu Bakar Jabir. Minhajul Muslim. Musthofa 'Aini dkk (penerjemah)

Al-Zuhaili, Wahbah. (1989). al-figh al-Islam Wa'adillatuhu. Suriah: Dar al-Fikr.

Amzmus, Zai. (2013). Hukum Perjanjian Syariah, diakses tanggal 25 November 2013. http://amzamus.blogspot. com/2013/09/hukum-perjanjiansyariah.html

Anwar, Syamsul. (2007). Hukum Perjanjian Syari'ah: Studi tentang Teori Akad dalam Fikih Muamalat. Jakarta: PT. Raja Grafindo Persada 
Iska, Syukri. (2012). Sistem Perbankan Moleong, Lexy, J. (2007). Metodologi Syariah di Indonesia dalam Perspektif Penelitian Kualitatif. Bandung: PT. Hukum Ekonomi. Yogyakarta: Fajar Remaja Rosdakarya Media Press. 